\title{
Proteger para não destruir: o Protocolo de Madri contra a exploração mineral na Antártica.
}

\author{
Protect not to destroy: Madrid Protocol against mineral \\ exploration in Antarctica
}

Luiane Magalhães Dias

\begin{abstract}
Resumo: $O$ presente artigo tem como objetivo evidenciar fatores que levaram do desmoronamento da Convenção para a Regulação das Atividades de Recursos Minerais Antárticos (CRAMRA) à adoção do Protocolo de Madri, um tratado internacional com mecanismos avançados para a proteção do ambiente antártico. Enquanto a primeira regulava o regime de exploração e explotação mineral na região antártica, o segundo estabelece o continente como reserva natural destinado à paz e à ciência, proibindo qualquer atividade relacionada à exploração mineral, por pelo menos, cinquenta anos. A assinatura do Protocolo de Madri preencheu uma lacuna no Sistema do Tratado da Antártica que se formou após a não-ratificação da CRAMRA. O método utilizado neste trabalho foi o levantamento bibliográfico, através da consulta de autores especialistas no assunto.
\end{abstract}

Palavras-chave: CRAMRA; Protocolo de Madri; Sistema do Tratado da Antártica.

Abstract: This article aims to understand the leading reasons to the failure of the Convention on the Regulation of Antarctic Mineral Resource Activity (CRAMRA) and the rise of the Protocol on Environmental Protection to the Antarctic Treaty, an international agreement containing advanced mechanisms to protect the Antarctic environment. The Purpose of CRAMRA was to regulate Antarctic mineral resources exploration and explotation, while the environmental protocol establishes the Antarctic continent as natural reserve devoted do peace and science, and prohibits all activities relating to Antarctic mineral resources, except for scientific research for at least 50 years. The environmental protocol filled a gap of the Antarctic Treaty System after the non ratification of CRAMRA. Literature review of relevant sources in the field was the research method used in this paper.

Keywords: CRAMRA; Madrid Protocol; Antarctic Treaty System.

\section{Introdução}

A Convenção para a Regulação de Atividades sobre Recursos Minerais Antárticos (CRAMRA), buscou solucionar questões que não foram resolvidas no Tratado da Antártica, assinado em 1959. Assim, motivados pela expectativa de existência mineral no continente austral, e se aproximando o ano de possível revisão do Tratado da Antártica, 1991 portanto, os países

Universidade de Brasília, UNB, Brasil. 
signatários do Tratado propuseram a criação do regime de exploração e explotação mineral na antártica (FERREIRA, 2009, p. 91).

Tratando-se de um tema delicado, a exploração mineral e preservação do intocável continente, as negociações da CRAMRA se prolongaram por seis anos, sendo marcadas por posições antagônicas entre os países e as organizações não-governamentais. O texto foi concluído em 1988, porém jamais foi ratificado. França e Austrália declararam contraditoriedade à Convenção, sendo que a última ainda propôs a ideia de constituir o continente como Parque Mundial (BLAY; TSAMENYI, 1990, p. 195).

Contudo, a não ratificação do regime de exploração mineral no continente austral, deu origem, paradoxalmente, ao mais detalhado documento multilateral já adotado na proteção internacional do meio ambiente (BLAY, 1992, p. 377), o Protocolo de Proteção Ambiental para o Tratado da Antártica ou Protocolo de Madri, como também é conhecido.

Este Protocolo estabelece um regime de uso do continente austral que agrida o mínimo possível o seu ecossistema, considerando-o reserva natural destinada à paz e à ciência. E prevê o banimento das atividades de exploração e explotação de petróleo e recursos minerais na região antártica por, pelo menos, cinquenta anos.

O presente artigo tratará inicialmente do Sistema do Tratado da Antártica, pano de fundo desses acontecimentos. Posteriormente trará foco à negociação da Convenção para a Regulação de Atividades sobre Recursos Minerais Antárticos, suas principais características e depois ao seu desmoronamento. E por fim, será tratado o Protocolo de Madri.

O método utilizado na construção deste artigo foi o de pesquisa com base documental com foco na revisão bibliográfica. A maior parte das fontes aqui utilizadas, foram de outros artigos acadêmicos especialmente encontrados em meio digital, mas a contribuição de livros impressos, pesquisas em portais internacionais e leitura de relatos sobre a época, foram essenciais para a construção deste trabalho.

\section{O Sistema do Tratado da Antártica}

Dos fins do século XVIII a meados do século XIX, a Antártica ficou marcada pela exploração comercial de focas e baleias ${ }^{2}$. Contudo, o Sexto Congresso Internacional de

Geografia, ocorrido em Londres nos anos de 1895, trouxe à Comunidade Internacional uma maior sensibilidade ao continente, e mais do que isso, recomendou que a comunidade científica de todo o mundo conduzisse expedições e relatasse suas pesquisas na Antártica (POLAR CRUISES [s.d]). Sendo assim, a atividade de exploração dos mamíferos apresentou um relativo declínio no início do século XX, acompanhado do desprestígio das nações por esse modo de operação (FERREIRA, 2009, p. 26).

\footnotetext{
2 Esses mamíferos marinhos despertavam grande interesse comercial, as focas pela pele e as baleias pelo óleo que era utilizado para iluminação, lubrificação e como matéria-prima para diversos usos, inclusive na construção civil e perfumaria, enquanto os ossos serviam para a confecção de utensílios. A busca por esses animais foi tão intensa que a sobre-exploração das focas quase levou a extinção daquelas espécies (FERREIRA, 2009, p. 26).
} 
Posteriormente, se seguiu a Era Heróica³ das Expedições Antárticas entre os anos de 1901-1917 (POLAR CRUISES [s.d]). Todo esse cenário, marcado pelo esforço de alguns países em exercer maior influência sobre o território antártico (LOOSE, 2012, p. 31), ensejou reivindicações territoriais no continente durante a primeira metade do século $X X$.

Portanto, entre os anos de 1908 a 1940, Grã-Bretanha, França, Austrália, Nova Zelândia, Noruega, Argentina e Chile, afirmaram unilateralmente suas soberanias sobre o continente antártico (FERREIRA, 2009, p. 27). Sem encontrar legitimidade perante a comunidade internacional, os pleitos territoriais conseguiram reconhecimento apenas entre eles mesmos. De um lado, os países da Europa e Oceania negociaram acordos entre si e reconheceram mutuamente suas reivindicações, do outro, os países latino-americanos, apesar de possuírem sobreposição na reivindicação territorial, se uniram e não aceitaram as demais reivindicações (LOOSE, 2012, p. 31).

Enquanto os Estados nacionais patrocinavam expedições e reivindicavam porções do continente antártico considerado res nullius ${ }^{4}$, a comunidade científica internacional abordou a

questão antártica partindo da iniciativa de novo Ano Polar Internacional. A ideia, encampada pelo hoje Conselho Internacional para a Ciência (ICSU), ampliou o escopo e promoveu o Ano Geofísico Internacional (AGI), nos anos de 1957-58 (FERREIRA, 2009, p. 39). Tal iniciativa contou com 50 estações de pesquisa na Antártica e mais de 5000 pessoas envolvidas. Para coordenar todas estas atividades foi criado o Scientific Comittee on Antartic Research (SCAR), ainda em atividade e com papel preponderante no Sistema do Tratado da Antártica (STA).

As atividades científicas na Antártica não foram encerradas com o término do AGI, e dada a forte presença da URSS na região, qualquer acordo que incluísse apenas os estados com pleitos territoriais mais os EUA e excluísse a outra superpotência do mundo bipolarizado, estava fora de cogitação ${ }^{5}$.

Por iniciativa dos Estados Unidos, motivados pelo temor de que os soviéticos estabelecessem bases militares na região e na descrença que uma solução satisfatória pudesse ser alcançada no âmbito das Nações Unidas, se propôs a realização de uma conferência visando o estabelecimento de um regime internacional para a Antártica (FERREIRA, 2009, p. 44).

Países territorialistas contrapuseram-se aos soviéticos os quais eram adversos a qualquer referência a reivindicações territoriais e favoráveis a um regime aberto à todas as nações (FERREIRA, p. 45). Como resultado buscando uma solução intermediária, o Tratado da Antártica suspende as reivindicações territoriais indefinidamente e impede que as atividades realizadas no escopo do Tratado possam ser utilizadas como fundamentos para futuros pleitos de soberania.

Além do congelamento das questões territoriais (Artigo IV), o Tratado da Antártica tem outros pontos fundamentais: o uso exclusivamente pacífico do continente (Artigo I), e a liberdade de pesquisa científica e cooperação internacional para esta finalidade (Artigos II e III).

\footnotetext{
3 A Era Heróica das expedições Antárticas recebe este nome pelas condições extremas enfrentada pelos seus expedicionários, as quais levaram à morte de muitos deles.

4 Território que não pertence a ninguém e passível de apropriação por qualquer Estado que lá estabelecesse soberania.

5 Para Villa, no contexto de Guerra Fria, a Antártica foi possivelmente, o único território, incluindo as áreas continentais e peninsulares, onde estas superpotências chegaram a um consenso mínimo para poupá-la dos efeitos do conflito (VILLA, 2011, p. 47).
} 
África do Sul, Argentina, Austrália, Bélgica, Chile, Estados Unidos, França, Japão, Noruega, Nova Zelândia e União Soviética foram os membros signatários originais do Tratado da Antártica. Desde sua assinatura, em 1959, outros 41 países aderiram ao Tratado. Os países signatários originais detém o status de "Partes Consultivas", com plenos direitos de participação e decisão nas Reuniões das Partes Consultivas (Antarctic Treaty Consultative Meetings, ATCMs). Demais países membros do tratado podem adquirir status semelhante, com direito de decisão, voto e veto no regime, desde que conduzam atividade científica substancial no continente, sendo que 17 países alcançaram estes requisitos, entre os quais o Brasil. As demais partes ao Tratado são convidadas a participar das reuniões, mas não dos processos de tomada de decisão (SECRETARIAT OF THE ANTARCTIC TREATY, 2013).

Atualmente, o Sistema do Tratado da Antártica inclui, além do Tratado, a Convenção para a Conservação das Focas Antárticas, a Convenção para a Conservação dos Recursos Marinhos Vivos da Antártica e o Protocolo sobre Proteção Ambiental para o Tratado da Antártica. Também compõem o STA as resoluções das Partes Consultivas do Tratado da Antártica, as decisões das Reuniões Consultivas Especiais e os resultados das Reuniões de Especialistas (FERREIRA, 2009, p. 55).

A construção do Tratado da Antártica representou a formação de um regime internacional sui generis, versando sobre o último ponto da terra sem soberania territorial reconhecida. O Tratado diz respeito a princípios, normas e regras sobre o ambiente Antártico a partir de 1959, que não somente passou a regular o continente, como também proporcionou um regime legítimo e exclusivo de governança sobre a região. $\mathrm{O}$ acordo vai em direção aos pressupostos que Krasner utilizou para definir um regime internacional :

os regimes podem ser definidos como princípios, normas e regras implícitos ou explícitos e procedimentos de tomada de decisões de determinada área das relações internacionais em torno dos quais convergem as expectativas dos atores. Os princípios são crenças em fatos, causas e questões morais. As normas são padrões de comportamento definidos em termos de direitos e obrigações. As regras são prescrições ou proscrições específicas para a ação. Os procedimentos para tomada de decisões são práticas predominantes para fazer e executar a decisão coletiva (KRASNER, 2012, p. 94).

\section{Antecedentes e Negociações que levaram à adoção da Convenção para a Regulação das Atividades de Recursos Minerais Antárticos}

A Antártica apresenta uma fonte potencial de minérios e petróleo, e mesmo difíceis de serem explorados ${ }^{6}$, anos atrás já despertavam o interesse dos Estados e empresas, o que levou à necessidade de uma regulamentação das atividades minerais que levasse em conta também a proteção dos recursos nativos. Assim, os países signatários do Tratado da Antártica, em meados da década

\footnotetext{
6 Para Ferreira, mesmo na hipótese da existência de um Eldorado no continente, a viabilidade econômica de sua exploração seria reduzida devido às dificuldades logísticas e aos custos para manter instalações, funcionários e escoar a produção, sem falar na necessidade de fontes de energia e na tecnologia para atravessar o manto de gelo (FERREIRA, 2009, p. 76).
} 
de 1970, se uniram para negociar um marco regulatório às atividades de recursos minerais no continente (GIBBONS, 1989, p. 3).

A questão da exploração de recursos minerais na Antártica foi discutida informalmente pelas Partes Consultivas do Tratado da Antártida (ATCPs) desde a sexta reunião do ATCM

(Antarctic Treaty Consultative Meeting) em 19707, mas foi apenas em dezembro de 1980 que uma reunião especial foi convocada dando início a um processo de negociação sobre um regime de exploração mineral. Reunindo-se novamente em março de 1981, em Buenos Aires, a comissão pedia o desenvolvimento do regime com urgência e estabeleceu uma reunião especial do ATCM. Em junho de 1982, a Reunião Especial do ATCM iniciou seu trabalho em Wellington, Nova Zelândia (FERREIRA, 2009, p. 77).

As reuniões se mantiveram até 1988, com uma média de duas sessões por ano, além das reuniões informais. O Embaixador neozelandês Christopher Beeby, foi o responsável por dirigir as sessões e por ter apresentado o projeto que seria a base da convenção, o Beeby Draft. Nesse contexto, iniciou-se uma corrida dos Estados para alcançar o status de Parte Consultiva, a cada sessão aumentava o número de países com poder de voto, começando com 14 em 1982 e chegando a 20 no final da Reunião Consultiva Especial (FERREIRA, 2009, p. 80).

Após dez reuniões, os ATCP's adotaram a Convenção para a Regulação das Atividades de Recursos Minerais Antárticos, em 02 de junho de 1988. Logo após o final da reunião foi expedido um Relatório Final que incorporava declarações e observações realizadas por vários delegados exteriorizando seus pontos de vista a respeito da Convenção (BLEY; TSAMENYI, 1990, p. 196).

Assim, após seis anos de esforços, trinta e três Estados concluíram as negociações para regular possíveis prospecções futuras, exploração e explotação de petróleo e outros minerais na Antártica. Esse foi o tempo necessário para intermediar as divergências entre os Estados reivindicantes e não-reivindicantes, desenvolvidos e em desenvolvimento, e os com interesses em recursos minerais e aqueles que tinham como pauta de prioridade o meio ambiente.

A CRAMRA forneceria uma estrutura para orientar futuras decisões sobre a possibilidade da exploração mineral na região Antártica, desconsiderando que alguma exploração ou explotação nunca ocorreria (GIBBONS, 1989, p. 3 e 4). Alternativas à Convenção incluíam declarar a Antártica fora dos limites de quaisquer atividades minerais.

\section{As Características Estruturais da CRAMRA}

A CRAMRA seria mais um instrumento jurídico dentro de um regime internacional que tinha como principal instrumento o Tratado da Antártica, portanto o quarto instrumento jurídico negociado no âmbito do Sistema do Tratado da Antártica, porém esse sub-regime não chegou a ser ratificado (LOOSE, 2011, p. 52). A área de aplicabilidade da CRAMRA seria o continente e as ilhas Antárticas, incluindo todas as planícies de gelo, localizadas ao sul do paralelo $60^{\circ} \mathrm{S}$ de latitude, no fundo do mar e subsolo das áreas próximas ao fundo do mar. Ao excluir da sua jurisdição as atividades de recursos

\footnotetext{
7 Em 1973, a Fundação Fridtjof Nansen adiantou-se nos estudos de impacto ambiental na Antártica através de um simpósio realizado na Noruega. Também em 1973, a Fundação Rockefeller, na Itália, promoveu uma reunião de especialistas em recursos minerais antárticos (VILLA, 2011, p. 50).
} 
minerais além da extensão geográfica da plataforma continental, a CRAMRA assegurar-se-ia que seus regulamentos não se aplicassem à atividades de mineração que pudessem ser dirigidas mediante a Convenção das Nações Unidas sobre o Direito do Mar de 1982 e monitoradas pelo Autoridade Internacional dos Fundos Marinhos (LOHAN e JOHNSTON, 2005, p. 18).

A CRAMRA entraria em vigor após a ratificação de pelo menos 16 Partes, dentre as quais dever-se-ia incluir 11 países desenvolvidos e 5 em desenvolvimento, os 7 territorialistas (Reino Unido, Austrália, Nova Zelândia, França, Noruega, Argentina e Chile) e as duas superpotências do contexto da Guerra Fria, EUA e URSS. Constituía um intrincado acordo composto por 66 artigos, que produziria um regime de regulação de atividades minerais na Antártica, através da antecipação da descoberta de jazidas comercialmente exploráveis, alcançando um aparente consenso entre a adequação das questões ambientais e o contencioso territorial (FERREIRA, 2009, p. 86).

\section{O Desmoronamento da CRAMRA}

As negociações da Convenção para a Regulação de Atividades sobre Recursos Minerais Antárticos nunca foram de fácil consenso, estenderam-se por seis anos (1982 a 1988) ao longo de 12 encontros especiais marcados pelo antagonismo entre as partes. Se por um lado estavam os países territorialistas, de outro estavam os que não haviam reivindicado soberania no continente (FERREIRA, 2009, p. 80).

Além disso, diversos atores entraram nas negociações e representaram empecilhos aos países territorialistas ${ }^{8}$. O Movimento dos Países Não Alinhados, por exemplo, encabeçado pela Malásia, propunha a divisão dos benefícios da exploração da Antártica com o resto do mundo e a transferência das responsabilidades delegadas às Partes Consultivas para a Organização das Nações Unidas. Os futuros emergentes Brasil, Índia, China e Uruguai reivindicavam um reconhecimento diferenciado na fórmula da Convenção (FERREIRA, 2009, p. 81).

Entretanto, o mais forte empecilho veio da organização "Antarctic and Southern Ocean Coalition" (ASOC), uma organização criada em 1978, tendo como um de seus fundadores o advogado ambientalista estadunidense, James Barnes. A ASOC problematizou as negociações secretas das Partes do Tratado da Antártica sobre a prospecção de mineral e gás no continente, de modo que bloquear a ratificação da CRAMRA tornou-se o grande objetivo da rede (ASOC.ORG [s.d]) ${ }^{10}$.

A ASOC representava um consórcio de mais de 175 grupos ambientais conservacionistas (MCCOLLOCH, 1992, p. 215), entre eles a proeminente Greenpeace. Em 1988, a organização pu-

\footnotetext{
8 Conforme Tomassini (1984) as relações internacionais contemporâneas apresentam, em primeiro lugar, grande diversificação de centros de poder, cuja atuação deixa de ser pensada em função do Estado para incorporar a sociedade civil organizada (apud VILLA, 2011, p. 46).

9 Conforme Ferreira, em 1983 a Malásia conseguiu introduzir a pauta da Antártica na agenda da Assembleia Geral das Nações Unidas. O argumento utilizado era de que o STA assemelhava-se a uma ocupação colonial, visto que a Antártica não pertencia às Partes Consultivas, logo não tinham direito de explorar um território que pertencia à toda humanidade. Essa iniciativa tinha o objetivo de arruinar as negociações da CRAMRA e de outorgar às Nações Unidas as responsabilidades incumbidas às Partes Consultivas (FERREIRA, 2009, p. 81 e 83).

10 Conforme Guerreiro (1992, p. 110-117) a resistência da ASOC à CRAMRA era infundada uma vez que a questão ambiental permeou toda a convenção: os Artigos IV, XII, XV, XVI da CRAMRA incorporaram Recomendações relativas à conservação e redução do impacto ambiental que foram aprovadas ao longo das ATCMs, tornando portanto, juridicamente vinculantes medidas que antes tinham caráter predominantemente exortativo (apud Ferreira, 2009, p. 87).
} 
blicou um relatório denunciando a maioria dos países que mantinham estações na Antártica por não cumprimento a medidas de proteção ambiental determinadas nas ATCMs ${ }^{11}$. Além disso, dois acidentes em 1989 contribuíram para reforçar a opinião pública de cautela à exploração mineral: o vazamento do petroleiro Exxon Valdez na costa do Alasca e o naufrágio do navio argentino Bahía Paraíso, vazando uma quantidade considerável de combustível (LOOSE, 2012, p. 75).

Embora a CRAMRA representasse a possibilidade de permissão para exploração e explotação de recursos minerais que deveria ser decidida caso a caso, é razoável supor que a Austrália, país com maior reivindicação territorial no continente ( $42 \%$ do território), não fosse favorável a um regime composto por diversos países e interesses, sem contar que a militância ambiental já estava bastante desenvolvida à época, neste país (FERREIRA, 2009, p. 88).

Assim, o dissenso entre países territorialistas, os não reivindicantes, menos desenvolvidos e mais desenvolvidos tecnologicamente, teve maior força com a dialética ambiental, que tendo

sido incorporada pela rede ASOC ${ }^{12}$, influenciou decisivamente no desmoronamento da CRAMRA.

Nessa conjuntura, em abril de 1989, a França retirou apoio à CRAMRA, algumas semanas depois o primeiro ministro da Austrália, Bob Hawke, não apenas declarou a oposição do seu país com a Convenção como também sugeriu que seria favorável a uma Declaração que transformasse a Antártica em um Parque Mundial ou em uma Reserva natural (MCCOLLOCH, 1992, p. 216). Índia, Bélgica e França também declararam apoio a essa ideia (BLAY e TSAMENYI, 1990, p. 195). De fato, nesse momento o regime do Sistema do Tratado da Antártica não foi baseado apenas em cálculos de interesse de curto prazo (KRASNER, 2012, p. 95).

A Austrália representa uma das Partes consultivas mais influentes do Tratado da Antártica, uma vez que está presente desde o seu surgimento e que reivindicava $42 \%$ do continente (BLAY e TSAMENYI, 1990, p. 195). No interior do país, enquanto o Conselho de Indústria Mineral pressionava o governo para a ratificação da CRAMRA, grupos conservacionistas ambientais, aconselhavam o governo a não seguir a Convenção (BLAY; TSAMENYI, 1990, p. 197 e 198) ${ }^{13}$.

Deste modo, a questão ambiental foi declarada pela Austrália como motivação para a rejeição da CRAMRA. É de se destacar que na política doméstica a proposição de tornar a Antártica um Parque Mundial, representou um grande recurso. Assim, para o governo, rejeitar a CRAMRA correspondia ao público interno e externo, uma postura responsável ambientalmente (BLAY e TSAMENYI, 1990, p. 200). Também, a Convenção não previa royalties para as partes reivindicantes em caso de exploração, ponto de forte interesse da Austrália. Portanto, preservar o continente austral foi possivelmente a melhor opção para o país. Como pondera Keohane, as escolhas no sistema internacional serão influenciadas de maneira a conferir maior peso às preferências dos atores mais poderosos (KEOHANE, 1982, apud KRASNER, 2012, p. 95) e de certo modo, foi isso que ocorreu na CRAMRA dentro do regime Antártico.

\footnotetext{
"O Relatório produzido pelo Greenpeace denunciava que apenas três estações, entre elas a brasileira, cumpriam as medidas determinadas nas ATCMs quanto à proteção ambiental (FERREIRA, 2009, p. 88).

12 Conforme Villa, a Antártica, passou a ser um teatro onde se desenvolve uma ampla atividade de atores não-estatais preocupados com os desequilíbrios ecológicos que uma eventual exploração de seus recursos minerais poderia gerar no âmbito mundial (VILLA, 2011, p. 48).

13 Segundo Blay e Tsamenyi, as rejeições australianas são, em parte, motivadas também por considerações econômicas, pois havia uma certa preocupação de que não houvesse na CRAMRA mecanismos anti-subsídio, o que
} 
Estava se aproximando 1991, o ano de possibilidade de revisão do Tratado da Antártica ${ }^{14}$ e qualquer movimento que representasse a busca pela permanência da CRAMRA, como era inicialmente a postura dos Estados Unidos, Reino Unido e Nova Zelândia (BLAY; TSAMENYI, 1990, p. 195), poderia resultar no desmoronamento do Tratado da Antártica.

Com o abandono da CRAMRA, reapareceu o vácuo regulamentar relativo à exploração mineral. Logo que não foi ratificado o regime de permissão para atividade exploratória, deveria então lançar-se uma política de preservação desses recursos. Deste modo, o debate sobre exploração de recursos minerais cedeu espaço aos debates relativos à proteção do continente (MCCOLLOCH, 1992, p. 215).

$\mathrm{Na}$ XV ATCM foi realizada uma Reunião Consultiva Especial para negociar um regime de proteção ambiental no continente antártico. As negociações se seguiram em quatro sessões, sendo a primeira no Chile e as posteriores na Espanha. Sendo concluído na cidade de Madri, em outubro de 1991, o Protocolo de Proteção Ambiental para o Tratado da Antártica (FERREIRA, 2009, p. 89).

\section{O Protocolo de Proteção Ambiental para o Tratado da Antártica}

poderia ser prejudicial à indústria mineradora australiana, uma vez que o país produzia minerais que poderiam ser encontrados na Antártica. E também a ausência de provisões de royalties às partes territorialistas deixaram o país insatisfeito (BLAY; TSAMENYI, 1990, p. 199).

O Protocolo de Madri entrou em vigor em 1998, e como descrito no sétimo artigo: Qualquer atividade relacionada com recursos minerais, salvo a investigação científica, deve ser proibida. Assim, conforme o artigo XXV, o Protocolo estabelece o banimento da exploração e explotação de petróleo e recursos minerais no continente por pelo menos cinquenta anos. Portanto até o ano 2048, está proibido o regime exploratório mineral no continente austral (PROTOCOLO DE MADRI, 1998).

O Protocolo, complementar ao Tratado da Antártica, é dividido em vinte e sete artigos e mais seis anexos, e visa estabelecer um regime de uso do continente austral que agrida o mínimo possível seu ecossistema. Foi um regime resultante não apenas da mobilização de grupos ambientalistas, mas também de uma estratégia para evitar uma potencial discórdia internacional (MCCOLLOCH, 1992, p. 211).

Deste modo, seu texto prevê que a Antártica continue sendo utilizada exclusivamente para fins pacíficos, e estabelece como objetivo a proteção abrangente do ambiente antártico e do ecossistema que lhe está associado, consagrando-a reserva natural, destinada à paz e a ciência, levando em consideração os seus padrões climáticos e meteorológicos, a qualidade da água e do ar, os ambientes terrestres, atmosférico, glaciário e marinho e as espécies da fauna e flora (PROTOCOLO DE MADRI, 1998).

Para tanto, postula que as atividades realizadas no continente devem limitar os impactos adversos no meio ambiente antártico, estabelecendo princípios, procedimentos e obrigações, à realização de pesquisa científica, mesmo às organizações não governamentais (FREITAS, 2008, p. 23).

Outro ponto importante do Protocolo é o princípio da Cooperação, constante no artigo VI, o qual estabelece que cada parte se comprometa, na medida do possível, partilhar informações que

\footnotetext{
14 Foi estabelecido no Tratado da Antártica, conforme o artigo XII, que após trinta anos, portanto em 1991, seu funcionamento poderia ser revisto (TRATADO DA ANTÁRTICA, 1975).
} 
possam ser úteis para outras partes no planejamento e na condução das suas atividades na área do Tratado da Antártica (PROTOCOLO DE MADRI, 1998).

Além disso, seus artigos preveem a realização de inspeções para a garantia de cumprimento do Protocolo e ações de respostas emergenciais, estabelecendo planos de contingência em caso de incidentes com potenciais efeitos adversos sobre o ambiente antártico ou ecossistemas dependentes e associados (PROTOCOLO DE MADRI, 1998).

O Protocolo cria, através do artigo XI, o Comitê para Proteção Ambiental, com a função de emitir pareceres e formular recomendações para o exame durante as ATCMs (LOOSE, 2012, p. 79). É imperativo também a apresentação de um Relatório anual sobre as medidas tomadas para implementação do Protocolo que deverão ser distribuídos a todas as partes e ao Comitê. O Protocolo dispõe também da opção de escolha pelas partes dos meios para a resolução de litígios, sendo eles o Tribunal Internacional de Justiça e ou um Tribunal Arbitral (PROTOCOLO DE MADRI, 1998).

Importante ressaltar, que no início dos anos 90, com o fim do Império Soviético e o consequente fim da Guerra Fria, a Organização das Nações Unidas se direcionou a temas mais universalistas e que até então não tinham grande vigor na agenda internacional, a temática do Meio Ambiente foi um deles. Assim a promoção do Protocolo de Madri caminhava em direção a uma Conjuntura maior de Proteção Internacional do Meio Ambiente, embora objetivos científicos e de proteção do meio ambiente antártico nunca tenham estado ausentes nos projetos para a Antártica desde o ano Geofísico Internacional'5.

\section{Considerações Finais}

A CRAMRA, ao tentar regular as questões minerais e petrolíferas na Antártica, esbarrou em pontos muito complexos, a se destacar a situação dos pleitos territoriais que não foram definitivamente resolvidos no Tratado da Antártica; a posição cada vez mais proeminente de atores internacionais até então menos evidentes (que no caso dos países com menor desenvolvimento relativo ficou marcado pelo Movimento dos Países Não Alinhados, e quanto às organizações não governamentais ficou marcada pela rede ASOC) e a dificuldade de se manter um equilíbrio entre preservar o último continente intocado e atender às demandas para o estabelecimento de princípios à atividade exploratória.

A sua não ratificação correspondeu justamente à dificuldade de se encontrar um consenso que satisfizesse os diversos atores envolvidos no tema e a grandeza da mobilização de grupos conservacionistas ambientais, em um cenário de mudança de conjuntura marcado pelo fim da

Guerra Fria. Assim, a formulação do Protocolo de Proteção Ambiental para o Tratado da Antártica, mais do que os esforços para a preservação ambiental representou uma estratégia de consenso entre as partes envolvidas.

O Protocolo por sua vez, traz um modelo alternativo de convivência internacional que colocou fim por pelo menos até 2048 ao imbróglio da questão mineral, representando hoje uma escolha muito

\footnotetext{
15 Para Villa, nas últimas décadas, o sistema internacional, limitado ao tradicional objeto das relações de poder entre Estadosnações, começou a ampliar sua agenda com o surgimento de novos temas como o caso do ecologismo (VILLA, 2011, p. 47).
} 
mais assertiva do que a CRAMRA, pois com a popularização dos discursos sobre o aquecimento global e a sustentabilidade, preservar o último continente inexplorado representa uma necessidade. Ou seja, se era mais valorizado promover a exploração mineral e de petróleo naquela época, hoje promover a preservação ambiental é um feito muito mais caro perante a comunidade internacional.

\section{Referências}

ASOC. History of Antarctic and Southern Ocean Colisation. Disponível em: https://www.asoc. org/about/history. Acesso em: 3 fev. 2019.

BLAY, S. K. N.; TSAMENYI, B. M. Australia and the Convention for the Regulation of Antarctic Mineral Resource Activities (CRAMRA). Polar Record, v. 26, n. 158, p. 195-202, 1990. Acesso em: 3 fev. 2019. https://doi.org/10.1017/s0032247400011438

DISCOVERING ANTARCTICA. Antarctic Territorial Claims. Disponível em: https://discoveringantarctica.org.uk/how-is-antarctica-governed/geopolitics/geopolitics-of-antarct ica/. Acesso em: 15 fev. 2019.

FERREIRA, Felipe Rodrigues Gomes. O sistema do tratado da Antártica: evolução do regime e seu impacto na política externa brasileira. Brasília: Fundação Alexandre de Gusmão, 2009.

FREITAS, Cilene Alves Menezes. Brasil e ano polar internacional: Ciência Antártica numa perspectiva política. Monografia (Especialização em Relações Internacionais) - UNB, Brasília, 2008. Disponível em: http://bdm.unb.br/bitstream/10483/1144/1/2008_CileneAlvesMenezesFreitas.pdf. Acesso em: 15 fev. 2019. https://doi.org/10.26512/2008.tcc.1144

GIBBONS, John H. Polar Prospects: A Minerals Treaty for Antarctica. U.S. CONGRESS, OFFICE OF TECHNOLOGY ASSESSMENT. Washington DC, September 1989. 218 páginas. Disponível em:

https://www.princeton.edu/ ota/disk1/1989/8926/8926.PDF. Acesso em: 4 fev. 2019.

KEGLEY, Charles William; BLANTON, Shannon Lindsey. World Politics: Trend and Transformation. 2010-2011. Boston: Cengagi Brain, 2011.

KRASNER, Stephen D. Causas estruturais e consequências dos regimes internacionais: Regimes como variáveis intervenientes. Revista de Sociologia Política, v. 20, n. 42, p. 93-110, 2012. https:// doi.org/10.1590/s0104-44782012000200008

LOHAN, Dagmar; JOHNSTON, Sam. Bioprospecting in Antarctica. UNU-IAS Report. 31 páginas, 2005.

LOOSE, Fabrício Ferreira. Bioprospecção na Antártida: O grande desafio dos membros do regime antártico no início do século XXI. Curitiba: Appris, 2012.

MCCOLLOCH, R. Rodney. Protocol on Environmental Protection to the Antarctic Treaty. The Antarctic Treaty. Antarctic Minerals Convention. Wellington Convention. Convention on the Regulation of Antarctic Mineral Resource Activities. Georgia Journal of International and Comparative Law, v. 22, n. 1, p. 232-211, 1992. Disponível em: https://digitalcommons.law.uga.edu/gjicl/vol22/ iss1/8. Acesso em: 3 fev. 2019. https://doi.org/10.1007/978-3-642-76732-6 5 
POLAR CRUISES: Heroic Age: The Heroic Age of Antarctic Exploration [s.d]. Disponível em: https://www.polarcruises.com/polar-info/antarctica-info/heroic-age. Acesso em: 7 fev. 2019. https:// doi.org/10.1017/s0032247411000222

BRASIL. Presidência da República. Protocolo ao Tratado para a Antártica sobre a proteção do meio Ambiente. 1998. Disponível em: http://www.planalto.gov.br/ccivil_03/decreto/D2742.htm. Acesso em: 3 fev. 2019.

BRASIL. Presidência da República. Tratado da Antártida. 1975. Disponível em: http://www. planalto.gov.br/ccivil_03/decreto/1970-1979/D75963.htm. Acesso em: 15 fev. 2019.

SECRETARIAT OF THE Antarctic Treaty. The Antarctic Treaty. 2013. Disponível em:

https://www.ats.aq/devAS/ats parties.aspx?lang=e. Acesso em: 8 fev. 2019.

VILLA, Rafael A. Duarte. Atores não-estatais e meio ambiente nas relações internacionais Greenpeace e a Antártica. Desenvolvimento e Meio Ambiente. n. 4, p. 45-57, jul./dez. 2001. https:// doi.org/10.5380/dma.v4io.3039

\section{Anexos}

\section{Anexo 1 - 0 Protocolo de Madri no Sistema do Tratado da Antártica}

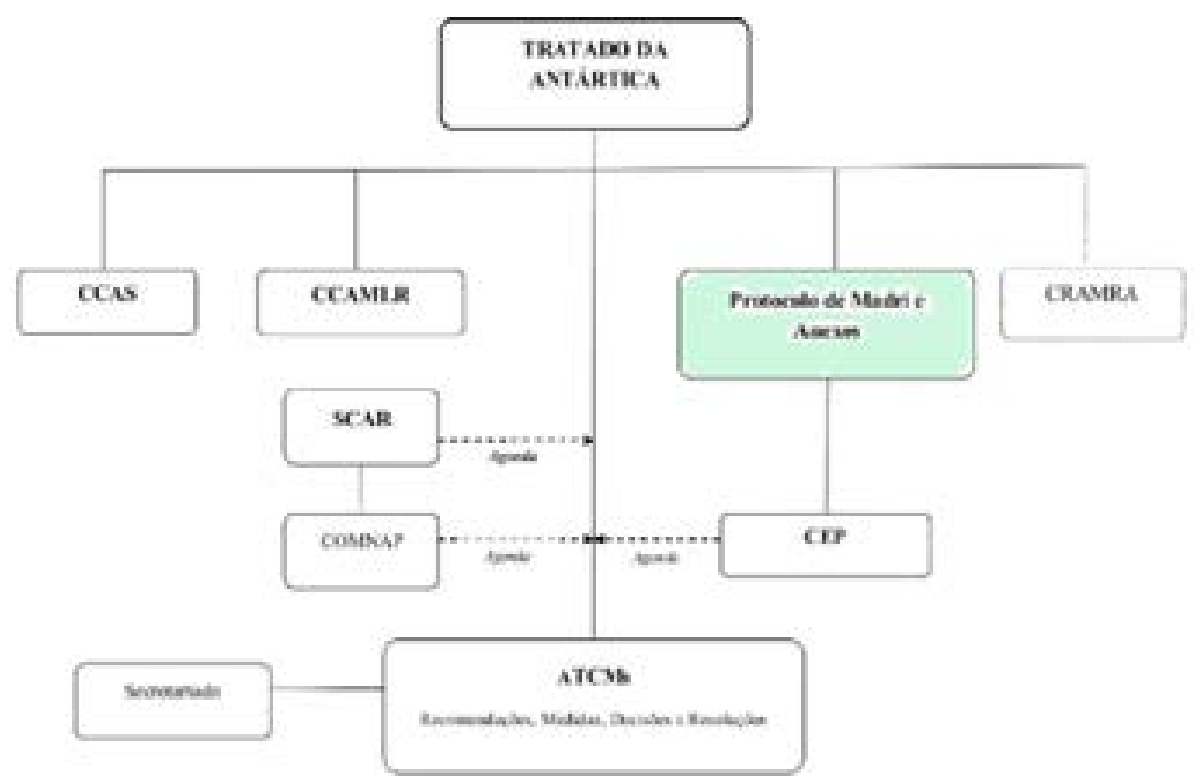

ATCM: Reunião Consultiva do Tratado da Antártica; CCAMLR: Convenção para Conservação dos Recursos Marinhos Vivos da Antártica CCAS: Convenção para Conservação das Focas Antárticas; CEP: Comitê para Proteção Ambiental; COMNAP: Conselho de Gestores dos Programas Nacionais Antárticos; CRAMRA: Convenção para Regulação de Atividades sobre Recursos Minerais Antárticos SCAR: Comitê Científico para Pesquisa Antártica. Fonte: FERREIRA, 2009, p. 114, adaptado. 


\section{Anexo 2 - Reivindicações territoriais na Antártica}

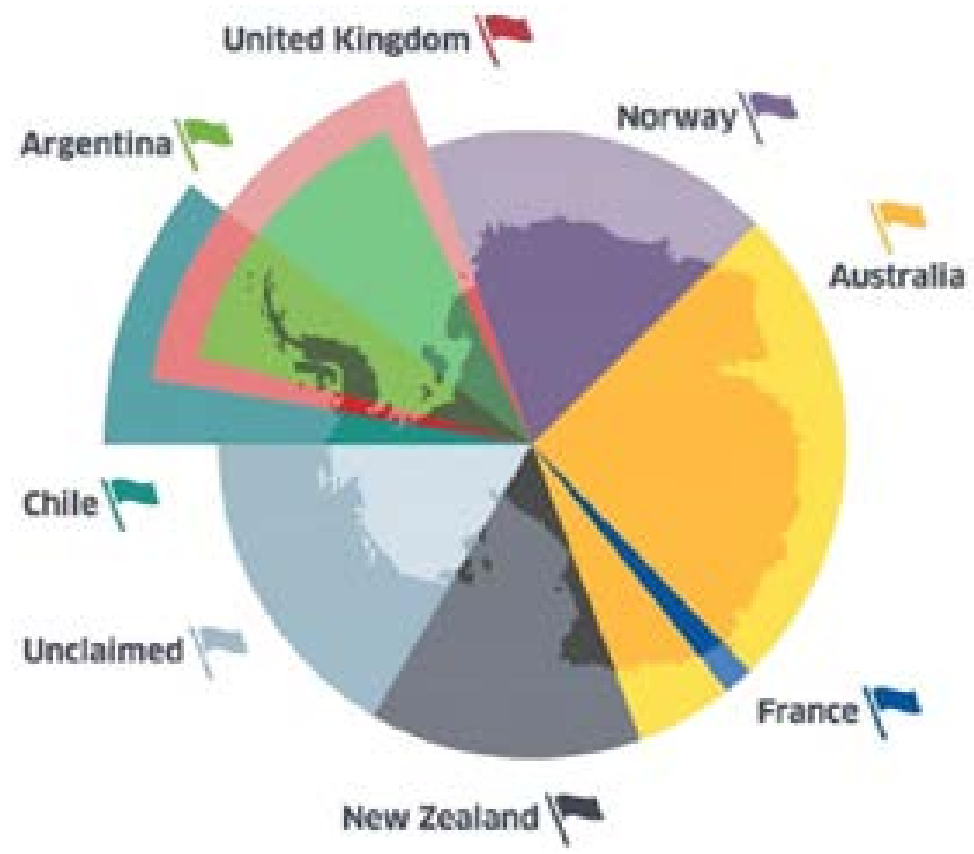

Fonte: Discovering Antarctica. org [s.d]

Recebido em: 15/02/2019

Aceito em: 21/05/2019

\section{Biografia do Autor}

\section{Luiane Magalhães Dias}

Possui curso técnico profissionalizante pelo Instituto Federal do Norte de Minas Gerais - Campus (2012) e ensino fundamental primeiro grau pela E. E. Prof. Claudemiro Alves Ferreira (2009).

ORCID: http://orcid.org/0000-0001-5107-73993;

EMAIL: luianemdias@gmail.com

Instituição: Pontifícia Universidade Católica do Rio Grande do Sul.

Localização: Av. Ipiranga, 6681 - Partenon - Porto Alegre/RS 